\title{
Teaching IT to Managers or Teaching Management to Engineers? None of the Above
}

\author{
Jaime Navón C. \\ Pontificia Universidad Católica de Chile (PUC) \\ Vicuña Mackenna 4860 (143), Santiago, Chile \\ jnavon@ing.puc.cl
}

\begin{abstract}
Information Technology (IT) has been the greatest wealth generator of the last two decades and there is an increasing number of managers who see IT as a strategic weapon and want to harvest their profits. MBA programs are starting to incorporate IT but many times this component gets relegated to one or two irrelevant courses that nobody likes. The opposite direction of adding one or two courses of management to a typical IT program will not produce the future CEO that is needed. We present here our experience with a new program that takes the best of the two worlds. A balanced curriculum (50-50) can be made strong enough in management and in technology. The mixed background of students produces a rich environment where students with business backgrounds benefit from students with IT backgrounds and viceversa. The preliminary evaluation of this experience is very positive.
\end{abstract}

\section{Introduction}

Information Technology (IT) is considered a strategic element for companies and organizations. This has resulted in MBA programs incorporating this subject into their curricula. Since many managers graduate from these programs it is critical that these programs provide sound education in IT. For these students to wholly understand how to take advantage of the new opportunities generated by IT and to face its risks and limitations, contents and methodology must be carefully designed. The challenge is keeping motivation high even when the material is rather technical for this audience. 
Most of the modern management trends are based on technology: CRM, reengineering, e-commerce, e-business and globalization among others. The dotcom revolution increased the visibility of IT by showing the common people that technology could generate impressive valuations. IT went from being a "nerds" topic to being discussed in the highest boards of directors.

Many MBA programs have incorporated IT in their curricula, most of the time as a single course which covers diverse aspects, from hardware and software fundamentals to data mining and electronic commerce. One problem with these courses is that they usually fail to become popular core courses [3] and, even worse, they do not achieve the goal of producing a change in the future manager's "palette" of options in such a way that he or she may make the most of the opportunities generated by the technology.

We are exploring a somewhat different approach. Last year we started a new program, called Masters of Information Technology and Management (MTIG) ${ }^{13}$, in which both information technology and management are first class citizens. The curriculum includes $50 \%$ of courses that are similar to the ones in a typical MBA program, and $50 \%$ of courses with information technology contents. Furthermore, we achieved a tight integration of these two fields through the following strategies:

- the mix of students (50\% have business degrees, $50 \%$ have engineering degrees)

- IT instructors teach with the business perspective in mind (real life examples rather than textbook)

- Instructors of management courses incorporate as much technology as possible

The graduates from this program are, therefore, business people who learn about the new possibilities that IT brings, and also engineers or computer science graduates who learn how this wonderful technology can be used to generate value or to make the organization more efficient. In either case, this is a person who is very well equipped to become the $\mathrm{CIO}$, or even the CEO, of a company where technology plays a crucial role.

\section{The MTIG program}

We describe here only the most distinctive characteristics of the program.

\subsection{Short courses}

We realized quite early that the typical semester-long (10 credit hour) courses were inappropriate for our purposes. We needed to cover many different subjects in a short period of time. The solution was to design half-semester courses ( 5 credit hours), so a student could do 20 or 24 courses in one year instead of just 10 or 12 . This solution still allows us to accommodate an unusually large course by cutting it into two courses that must be taken in two consecutive periods.

${ }^{13}$ MTIG corresponds to the Spanish (Magister en Tecnologías de Información y Gestión) 


\subsection{Non-exclusive dedication}

Although the program could be perfectly offered in a full-time dedication format, we decided to start with an evening-only class format.. The decision was based on information we have collected about the potential market for this program: there was a lot of interest among working engineers and managers but nobody would quit his job to enroll in a graduate program. Since we were specially interested in providing these new skills to people who were already in management positions, the best option was to create a part-time program with classes after the regular working hours.

\subsection{Duration of studies}

The students take only three courses simultaneously (12 courses in one year). The program comprises a total of 24 courses, so it will take about two years for a student to complete the program. During the last semester, the student must also do an individual capstone project. In most cases this project is carried out for the company where the student works. We knew from past experience that this academic load (three courses) is the maximum that a person with a full-time job (especially IT jobs!) can handle without risk of massive failure.

\subsection{Methodology}

The first problem we had to face is how to teach the hard IT courses to a group that was heterogeneous (many of them already knew a lot of IT) and not necessarily technology motivated (at least half of the group).

Although about $60 \%$ of the MBA programs include an IT course [2], students usually are dissatisfied with it and this course, which should be a key course in their formation, simply becomes a barrier to overcome. Frequently this is due to an excessive technical approach which is dissociated from what the student is really interested in: in what way will IT make a better manager of him and how can he take advantage of the new opportunities opened by IT. According to Bacon and Fitzgerald [3], "They tend to expect practice-related, insightful, integrated themes, with useful models that they can take away and use".

We believe that learning by doing is a great way to increase motivation among non-technically-oriented students. For example, instead of giving a power point presentation about the internet, we help them to put together an e-commerce site of their choice. All our IT courses have lab sessions whose purpose is not to teach some specific skills or how to use some software tool, but to keep the students interested in the technology.

A big challenge is how to design the lab sessions such that people with little or no previous technical skills can complete the job, but at the same time the students with the knowledge do not get bored. We solved this dilemma by building every lab experience as a series of small steps. Everybody must do the first 3 or 4 steps. The more experienced students are encouraged to do 5 or 6 steps and receive detailed feedback of their work as a reward. When time is up everybody is tired but quite happy and proud of what has been accomplished. 
For instance, the internet course started with a lab experience in which students interact directly with a web server through a simple terminal emulator. The first steps were simple GET requests and then it got more and more involved including specific headers, etc. It was easy to talk about the HTTP protocol after this.

\subsection{The capstone project}

As we said before, during their last semester in the program, the students must develop a short IT project. This project, in most cases, is developed for the company the student works for, which provides also a sponsor who also serves on the student committee. After a six-month period the student must make a public presentation of her work in front of the members of a committee.

The project itself can go from "how to generate business value through business intelligence tools" to "design of a dimensional model for management control" to "feasibility of biometric authentication techniques in small to medium organizations", etc. The goal is to show that she is capable integrating the new knowledge to solve real problems or situations.

\section{The experience}

A month after we announced the program and with almost no advertising at all we got many phone calls asking for more details. Our web site got hundreds of visits and many prospective students left their contact information. Even though we had detected the demand before, it was a pleasant surprise to confirm our suspicions. Many of the respondents said they felt this program responded to their needs much better than a Masters in IT or an MBA program. We got a full enrolment (35 students) for the first year only one month after the program was announced. Many of the students said this was just the program they were looking for.

It is still too early to perform a full evaluation, but so far we feel that the students are quite happy. The feedback information is collected through opinion polls that the students complete after each course and also through meetings with a group of students with very different backgrounds. More than $80 \%$ say they are happy or very happy with the program. Students with a business background said that only some courses were really hard but nevertheless they enjoyed them and learnt a lot of new things. More important yet, they said that the technological courses were the most interesting and that the new stuff they had learnt changed their view of IT.

Computer science or IT students found the management courses the most interesting (no surprise), but they still enjoyed the technically-oriented courses because there was new stuff that they never learnt before.

What students appreciated most was the heterogeneous composition of the group. The engineers could listen to questions and comments that would never have arisen in an all-IT group. Conversely, businessmen were exposed to the language and views of the IT people.

The instructors worked very hard. There are too many challenges here:

- heterogeneous group with very different backgrounds

- teaching hard technical stuff to people who are not very interested in it 
- combining lectures with labs to produce a more constructivist approach

- polishing the contents of most courses because they were all new courses In spite of all that, students are quite happy with the experience so far. They have all confirmed their participation for a new period and most of them are planning to make a few adjustments according to what they learnt from the first experience. Some teachers who were initially quite skeptical changed their minds completely.

\section{Conclusion}

An increasing number of managers see IT as a strategic weapon and want to harvest their profits. IT has been the greatest wealth generator for the last two decades. This can be expressed in several ways, for instance: in the U.S., during the 1995-1999 period, $60 \%$ of productivity improvements and $40 \%$ of growth were explained by information technology [4].

Since many future managers come from MBA programs, it is reasonable to include the IT component in those programs. Until now not many successful experiences have been reported; often times, the technological component gets reduced to one or two electives and they are sought by students only as a barrier that needs to be passed. From the other side, graduate IT-only programs are weak on management and fail to attract the desired audience of decision-making people.

We have described our experience with a program that provides an alternative approach for producing the leaders that 21 st century companies require. The curriculum includes management and technology courses in equal proportion. The group of students includes businessmen and engineers. The methodology favors a constructive approach that allows keeping the non-techies interested and motivated. Although it is still too early to celebrate, the results so far are promising. There is a huge interest in the program and both the participating students and the instructors are quite happy. We will have to wait to have a more definitive answer.

\section{References}

1. Bacon, J. C. and B. Fitzgerald (2001). A systemic framework for the field of information systems. The Database for Advances in Information Systems 32(2): 46-67.

2. Burgess, S., C. Golam, et al. (2002). Student attitudes to MIS content in an MBA: a comparison across countries. Informing Science + IT Education Conference, Cork, Ireland.

3. Lucas, H. (1999). The state of the Information Systems field. Communications of AIS Volume 1, Article 5, January 1999.

4. Oliner, S. and D. Sichel (2000). "The Resurgence of Growth in the Late1990s: Is Information Technology the Story?" Journal of Economic Perspectives 14(4): 3-22. 